\title{
A Model for Developing of Surveillance, Prevention and Control the COVID-19 and Protection of People's Rights in a New Normal Way by a Virtual Community of Primary Health Care Service Network, Mahasarakham Province, Thailand
}

\author{
Rungrueng Kitphati ${ }^{a}$, Juraporn Krates ${ }^{b}$, Sopita Jitvigranc ${ }^{c}$, Kwanchai Nuchklang ${ }^{d}$, Rungrueang Sankosa ${ }^{\mathrm{e}}$, \\ Sanya Kenaphoom
}

\author{
${ }^{\text {a }}$ Office of permanent Secretary, Ministry of Public Health, Nonthaburi, Thailand \\ ${ }^{\mathbf{b}}$ Technical Office,Ministry of Public Health, Nonthaburi, Thailand \\ c,d,e Provincial Health Office,Mahasarakham, Thailand \\ ${ }^{\mathrm{f}}$ Rajabhat Mahasarakham University, Thailand

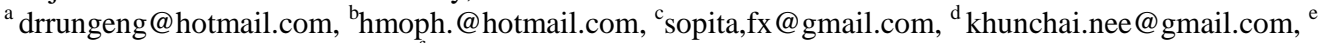

Roungreung_san@hotmail.com, ${ }^{\mathrm{f}}$ zumsa_17@ hotmail.com

Article History: Received: 10 November 2020; Revised 12 January 2021 Accepted: 27 January 2021; Published online: 5 April 2021

\begin{abstract}
Epidemic disease is extremely dangerous for humanity; coronavirus 2019 is another epidemic that has caused great damage to the nation. Every country tries to prevent, treat and resolve to overcome an epidemic situation like this. Therefore, this study aims to (1) Study the success elements of surveillance, prevention, and control of COVID-19 systems and protect citizens' rights in a new normal, (2) Analyze conditional factors that influence the success of surveillance, prevention, and control of COVID-19 and protection of citizens' rights. Ans (3) Developing a model for the development of surveillance, prevention, and control of COVID-19 and protect the rights of people in a new way by the virtual community of primary health service networks. This research method was Mixed Methods Research which was held at Mahasarakham Province, Thailand, and was divided into 3 phases; The first: Application of the Future Search Conference (FSC) technique to study the surveillance, prevention, and control of COVID-19 and protect the rights of people at the provincial, district, and sub-district levels, divided into 2 groups as follows (1) 60 the coach lecturer, and (2) 690 virtual community members in the provincial area,The content is then analyzed for theoretical conclusions. The second: A survey of 254 members of the coach lecturer and virtual community members of the primary health service network. The research instrument was an approximation scale questionnaire, which analyzed data using descriptive statistics and multiple regression analysis. And the third: Establish a model for the development of surveillance, prevention, and control of COVID-19 systems and to protect citizens' rights in a new way by virtual communities. Targeted by 20 experts to make the expert verify the system development model. The model was then improved to develop surveillance, prevention, and control of COVID-19 systems and to protect citizens' rights in a new way by appropriate virtual communities. The research results were found that:

1. The success of surveillance, prevention, and control of COVID-19 and the protection of civil rights in general is at a high level ( $=3.62, \mathrm{SD}=0.65$ ). ranking the mean from highest to lowest; establishing a virtual community information technology infrastructure for communicating, informing, forwarding, and displaying real-time information. The competency of personnel performing work in an emergency, the management mechanisms for epidemic situations, the public awareness and cooperation, and the channels of access to services that can be initially assessed and screened for risks $(=3.85,3.79,3.69$, 3.42and 3.35; S.D. $=0.61,0.59,0.63,0.67$ and 0.73 ) respectively.

2. Conditional factors influencing the success of surveillance systems, prevention, and control of COVID-19, and the protection of citizens' rights in new normal by the virtual community of the Primary Health Service Network found there were five statistically significant variables as follows: the public communication, the participation, and government measures, the information technology, the expectation of benefits, and Readiness to respond to health care situations. These predictor variables can jointly forecast the success of surveillance, prevention, and control of COVID-19 and protect citizens' rights in the new normal by the virtual community by 60.9 percent by statistically significant $(\mathrm{p} .05, \mathrm{R} 2=.609, \mathrm{~F}=194.641$ )

3. A development model for surveillance, prevention, and control of COVID-19 and protection of civil rights in new normality by an appropriate virtual community of primary health care networks consists of two main components: (1)The success elements of surveillance, prevention, and control of COVID-19 systems consist of 5 main elements and 35 sub-elements. (2) the conditional factors influencing success are five main components, 42 sub-elements. Therefore, this development model is highly appropriate, possible, and can lead to policy proposals to prepare, develop, and strengthen primary health care networks in a way Normal..
\end{abstract}

Keywords: Development Model; System of Surveillance, Prevent and Control COVID-19; Rights Protect; Virtual Community; Primary Health Care Service Network 


\section{Introduction}

The coronavirus 2019 is a new epidemic in the world, caused by a virus that transmits from animals to humans, and when it enters the body it causes the severe acute respiratory syndrome. Many strains of coronavirus cause respiratory diseases ranging from the common cold to severe illnesses such as Middle East Respiratory Syndrome (MERS) and Serious acute respiratory syndrome (SARS. The most recently discovered coronavirus has caused coronavirus 2019, or COVID-19, that has spread throughout all regions of the world, and the disease can be transmitted from person to person through nasal or mouth secretions emitted by people with COVID-19 when coughing or sneezing or speaking, these droplets are quite heavy and can spread within a distance of at least 1 meter and will quickly fall to the ground.COVID-19 exposure can be obtained from the inhalation of aerosol from a patient with pandemic coronavirus (WHO, 2020).

Currently, the situation of coronavirus 2019 has become a global public health problem that is pandemic in many countries, where the coronavirus 2019 started in China from December 30, 2019, to September 30, 2020, found that there are confirmed cases in 213 countries worldwide, 2 special administrative districts, 1 city-state, Diamond boat Princess, Grands Boat Princess, and MS ship Zaandam with 33,875,113 cumulative cases worldwide there were 65,996 severe cases, 1,013,195 deaths, and the top 10 countries with confirmed cases were The United States, 7,406,729 cases, India 6,229,474, Brazil 4,780,317, Russia 1,176,286, Colombia 824,042, Peru 811,768 , Spain 758,172 , Mexico 738,163 , Argentina 736,609 and South Africa 672,572 , China is $44^{\text {th }}$ with 90,529 cases, including Hong Kong 5,080, Macau 46 cases (Department of Disease Control, Ministry of Public Health, 2020). The situation with the highest number of infected in each continent was reported on August 3, 2020, with Africa (South Africa) 511,485 cases. North America is the United States, with 4,582,276 cases. South America is Haiti with 7,468 cases. Europe is Russia 856,264 , Oceania is Australia 17,923, Asia is India 1,803,695, which is a huge increase in numbers (WHO, 2020).

However, the situation of COVID-19 in Thailand found that the median number of confirmed cases of COVID-2019 was 36 years ( 1 month - 97 years), Male 2,012 cases, female 1,552 cases (male: female $=1.30: 1$ ), Thai nationality 3,165, other nationality 390 and unknown 9 cases, Have 213 history of an underlying disease and 3,351 no underlying disease. 40 cases of screening patients were found at the airport (including 1 Thai citizen returning from Wuhan). In-person hospitalized 1,588 cases. Infected by following 1,189 contacts, out of 626 statedesignated areas quarantine, the immigration of Songkhla Province 65 cases, Active Case Finding55 cases, and screened according to the criteria of other organizations 1 person (Ministry of Public Health, 2020). Thailand maintains intensive measures in the screening and quarantine process of persons entering the country, there are measures for communicating risks with people to avoid being in crowded places or in places with closed ventilation such as be in meeting rooms, exhibition centers, shopping centers, theaters, etc. If unavoidable to scan the QR code "Thai Won" every time entering-leaving the place with the use of a face mask or cloth mask all the time, spaced at least $1-2$ meters or 1-2 arms, and the shortest time to meet other people, including practice to personal hygiene. The cooperation of the people to monitor the fever and respiratory symptoms of people in the area, including foreigners who have recently arrived in the community, including foreign workers, tourists, etc., to be tested for the coronavirus 2019 and prevent the spread of the coronavirus in the community.

According to the aforementioned studies of the COVID-19 situation, it was found that around the world, including Thailand, it was predicted that the second round of the virus outbreak could lead to more or more seriousness. The impact of the outbreak not only affects public health, medical, and public health systems, but also the livelihoods of people and the economy at both the macro and micro levels of the country. The first wave of COVID-19 has resulted in a lot of lessons for prevention, disease control in Thai society, even though there were problems and obstacles in the beginning. However, such problems are solved very well by various systems and mechanisms of Thai society, the success of early COVID-19 control has been demonstrated by information on the state of emergency response system availability and management mechanisms, innovation both invention for disease control and medicine, social Mechanisms for Disease Prevention, which shows the strength of systems and mechanisms for disease prevention in society and in communities.

The success of the COVID-19 control of Thailand during the first outbreak of the previous outbreak, many provinces were able to manage and control the disease in the area very well under the management mechanism of the provincial governor as the commander of the emergency situation, and establishing operational guidelines under the government and the Ministry of Public Health, which found that many provinces did not find any reports of infection / sick in the area, many provinces are epidemic areas, but the disease can be controlled, many provinces are areas designated as State quarantine, and many provinces have areas that connect with neighboring countries and can prevent and control diseases. Mahasarakham Province can be an area that can manage disease prevention and control in the area as well, where there are no reports of infection and no epidemic of COVID-19 in the area, or there is no new infection or the number of new infections found to be able to control the situation of emergency without the COVID-19 epidemic, it is an important and interesting issue. 
However, each country rushes research to find ways to cope with the disease outbreak. Therefore, there were several studies have attempted to come up with strategies to prevent, correct and treat people affected by the virus outbreak. Hence, in order to synthesize knowledge based on experience, process components, and take lessons on the success of COVID-19 control operations,Including creating future models, images of the Thai community in new normal, the research team has performed "Research projects to develop surveillance systems, prevention, and control of COVID-19 and the protection of citizens' rights in new normal by the virtual community of the Primary Health Service Network". The findings will be developed for policy proposals to develop surveillance, prevention, and control of COVID-19 systems and to protect citizens' rights in new normal with a virtual community of primary health service networks, and expand the results or use them in other provinces.

\section{Research objectives}

This research aims to develop a model for the development of surveillance, prevention, and control of COVID19 , and protect people's rights in a new normal way by using virtual communities of the primary health care service network that studied in the area of Mahasarakham Province, Thailand

\section{Research Methodology}

This research was the mixedmethods research by using the qualitativeresearchand quantitative research which has a method for collecting data using a variety of scientific methods, differing according to the data source, and putting the research into 3 phases as follows:

The first: the qualitative research studied medical personnel groups at all levels of primary health care networks, other government personnel, representatives of community organizations, and the public sector involved in surveillance, prevention, and control of COVID-19 and protection of the rights of people throughout the province. By choosing the specific sample group, divided into 2 groups: (1) 60 people to create a coach lecturer of virtual community with the workshop and application of Future Search Conference - FSC. (2) 690 people are virtual community members who have experience in the implementation of surveillance, prevention, and control of COVID-19 systems and the protection of citizens' rights in the primary health service network areas of the 13 districts of Mahasarakham Province with the workshop and Future Search Conference-FSC technique. Each step of data collection was performed by recording audio, picture recording, and meeting recordings with notes and observations, performed with the methodological triangulation (Denizen, 1970). Then, using the typological analysis and content analysis for explaining, interpretation, and analytic induction, constant comparison refers to a research conceptual framework.

The second: The quantitative research was conducted on a sample of 750 of the coach lecturer and virtual community members of the Primary Health Service Network, Mahasarakham Province, the sample size was determined using the ready-made tables of Krejcieand and Morgan (1970) at 95\% confidence level and a sample size of 254 people. The research instrument was a questionnaire developed from the study of academic papers and the results of the last phase which was modeled on the Likert scale as a 5 five rating scale. Examining the quality of the research instruments by using questionnaires that were considered the content validity by three experts. and the reliability with Cronbach's alpha coefficient at 0.89. the statistics were Descriptive statistics, Pearson Product Correlation Coefficient, Multiple Linear Regression Analysis, which determines its significance at the 0.05 level. Finally created the conditional forecasting equations that influence the success of surveillance, prevention, and control of COVID-19 systems and protect citizens' rights in new normal by the virtual community.

The third: Establish and evaluating forms for the development of surveillance, prevention, and control of COVID-19 systems and to protect citizens' rights in new normal by the virtual community. This was started the drawing up a development model based on the strategy of research based on the following research-based strategies: (1) Analyzing the survey research results with the SWOTanalysis concept, (2) Analyzing the results of the TOWS Matrix analysis to design a development approach, and (3) A) Synthesis of development approaches to a model (Sanya Kenaphoom et al. 2020). The targeting the expert verify 20 people responsible for evaluating results, verifying the suitability of the development model, then the results are developed into a development model appropriate and practicable.

\section{Results}

1. The success elements of surveillance, prevention, and control of COVID-19 systems and the protection of citizens' rights in new normal by the virtual community of the primary health service network found that;

1.1Surveillance at both individual and household levels: In the past, the implementation of surveillance, prevention, and control of COVID-19 in provincial areas, which has been carried out from the individual to the government agencies were head of household, village health volunteer, community leader, district disease control committee, 
primary health service unit, district health promoting hospital, community hospital, district health office, provincial hospital, provincial health office. All levels of medical and public health personnel, especially the provincial governors and government officials at all levels have performed full surveillance, prevention, and control until Mahasarakham Province is free from infectious agents.

1.2 the well-being of the people has changed: A new lifestyle that is different from the original, becoming a new way of life or new normal, From brainstorming building a common future to a new norm of surveillance, prevention, and control of COVID-19 systems found that there was The form of behavior, operation, and communication of two or more people is becoming more and more technologically networked, especially wireless technology as a communication medium to form the virtual community, which does not need to meet face to face, nor need to walk, not necessarily to meet in one place, has become a new way of life where you always have to wear a face mask, spacing, washing hands, hand sanitizer, avoiding congested places, avoiding vulnerable groups or infected people with or without symptoms. These have become virtual communities where content can be communicated with each other, with wireless technology as the medium.

1.3the virtual community through technology network: It is a network that can communicate risks, forward and provide feedback or relate to real situations through social media intermediaries used in daily life such as mobile, LINE, Facebook, or real-time web app, which can display on the dashboard about risk areas, risk locations, risk groups, risk symptoms, and alert communication of risks in the virtual community.

1.4 the desirable success elements: In other words, the five components of the success of surveillance, prevention, and control of COVID-19 systems and the protection of citizens' rights are as follows: (1) Management mechanisms for epidemic situations, (2) Competency of personnel performing work in an emergency, (3) Establishing a virtual community information technology infrastructure for communicating, informing, forwarding and displaying real-time information, (4) Public awareness and cooperation, and (5) Channels of access to services that can be initially assessed and screened for risks.

1.5 The conditional factors associated with the success of surveillance, prevention, and control of COVID-19 and the protection of citizens' rights in new normal include: (1) personal factors were gender, education, and related performance, (2) knowledge about the COVID-19 Outbreak, (3) Expectation of benefits, (4) Participation and government measures, (5) Public communication, (6) Information technology, and (7) Readiness to respond to health care situations.

2. Analysis of the success of surveillance, prevention, and control of COVID-19 systems and the protection of citizens' rights in new normal by the virtual community of primary health care networks, found overall to be high level ( $\mathrm{X}=3.62$, S.D.=0.65), Sorting the mean from highest to lowest as follows:the establishing a virtual community information technology infrastructure for communicating, informing, the forwarding and displaying real-time information, the competency of personnel performing work in an emergency, the management mechanisms for epidemic situations, the public awareness and cooperation, and the channels of access to services that can be initially assessed and screened for $\operatorname{risks}(X=3.85,3.79,3.69,3.40$ and3.35: S.D. $=0.61,0.59$, $0.63,0.67$ and 0.73 ) respectively. The details according to table 1 :

Table 1Mean and standard deviation of success of surveillance, prevention and control of COVID-19 and protecting people's rights in a new normal

\begin{tabular}{l|c|c}
\hline $\begin{array}{l}\text { Success of surveillance, prevention and control of COVID-19 and } \\
\text { protecting people's rights in a new normal }\end{array}$ & $\mathbb{X}$ & SD \\
\hline $\begin{array}{l}\text { The management mechanisms for epidemic situations, the public } \\
\text { awareness and cooperation }\end{array}$ & 3.69 & 0.63 \\
The competency of personnel performing work in an emergency & 3.79 & 0.61 \\
The establishing a virtual community information technology \\
$\begin{array}{l}\text { infrastructure for communicating, informing, the forwarding and displaying } \\
\text { real-time information }\end{array}$ \\
$\begin{array}{l}\text { The public awareness and cooperation } \\
\text { The channels of access to services that can be initially assessed and } \\
\text { screened for risks }\end{array}$ \\
\hline Total
\end{tabular}


3. The condition factors for 9 variableswere the personal factor [gender (x1), education (x2), time Performance (x3)]Knowledge and understanding of COVID-19 outbreak(x4), Expectation of benefits(x5), Participation in government measures(x6), Public communication (x7), Information technology (x8), and Readiness to respond to health care situations $(\mathrm{x} 9)$ influencing the success of surveillance, prevention and control of COVID-19 and protecting people's rights in a new normal(y)with correlation coefficient (r) is between 0.125 to 0.675. In which no predictor variables pair had a correlation coefficient (r) higher than the agreement of Multiple linear regression analysis $(r<0.75)$. Therefore, every variable is suitable for the analysis of Stepwise Multiple linear regression according to the following table.

Table 2the stepwise multiple linear regression of the success Predictor variables of surveillance, prevention and control of COVID-19 and protecting people's rights in a new normal

\begin{tabular}{|c|c|c|c|c|c|c|c|}
\hline $\begin{array}{l}\text { Predictor } \\
\text { variables }\end{array}$ & $\mathbf{R}$ & $\overline{\mathbf{R}^{2}}$ & ed ${ }^{R^{2} \text { Adjust }}$ & $\begin{array}{r}\text { SE } \\
\text { est }\end{array}$ & $\begin{array}{c}\mathbf{R}^{2} \\
\text { change }\end{array}$ & $\mathbf{F}$ & p \\
\hline $\mathrm{x} 7$ & 0.751 & 0.515 & 0.510 & $4^{0.46}$ & 0.515 & $411^{194.6}$ & ** \\
\hline$\times 7 \times 6$ & 0.757 & 0.566 & 0.529 & $7^{0.42}$ & 0.051 & $47^{139.3}$ & ${ }_{* *} .000$ \\
\hline$\times 7 \times 6 \times 8$ & 0.770 & 0.585 & 0.542 & $8^{0.41}$ & 0.019 & $12^{100.6}$ & *.001 \\
\hline$\times 7 \times 6 \times 8 \times 5$ & 0.781 & 0.601 & 0.549 & $3^{0.41}$ & 0.016 & $\begin{array}{l}79.66 \\
0\end{array}$ & * .004 \\
\hline$\times 7 \times 6 \times 8 \times 5 \times 9$ & 0.787 & 0.609 & 0.601 & $0^{0.41}$ & 0.008 & $3 \begin{array}{l}65.95 \\
3\end{array}$ & * .017 \\
\hline
\end{tabular}

Table 2 found that the conditional factors influencing the success of surveillance systems, prevention, and control of COVID-19, and the protection of citizens' rights in new normal by the virtual community of the primary health service network, it was found that 5 factors were; the public communication, the participation and government measures, the information technology, the expectation of benefits, and the readiness to respond to health care situations by statistically significant ( $\mathrm{p} . \leq 05)$ which together predict success with an overall plural regression coefficient $(\mathrm{R})$ of .787 , quadratic predictive power $\left(\mathrm{R}^{2}\right)$ is equal to $.609, \mathrm{~F}$ value is $194.641, \mathrm{SEest}$ is \pm 0.410 , and the constant (a) is 0.211 that can be summarized according to the following table.

Table 3: Stepwise Multiple linear regression coefficient of predictor success variables in surveillance, prevention and control of COVID-19

\begin{tabular}{|c|c|c|c|c|}
\hline Predictor variables & $\mathbf{b}$ & $\boldsymbol{\beta}$ & $\mathbf{t}$ & $\begin{array}{c}\text { p- } \\
\text { value }\end{array}$ \\
\hline Public communication & 0.215 & 0.294 & 4.696 & $.000^{* * *}$ \\
\hline \multirow[t]{2}{*}{ Participation in government measures } & 0.283 & 0.256 & 4.335 & $.000^{* *}$ \\
\hline & 0.117 & 0.125 & 2.964 & $.003 *$ \\
\hline Expectation of benefits & 0.167 & 0.148 & 2.448 & $.015^{*}$ \\
\hline Readiness to respond to health care situations & 0.142 & 0.151 & 2.363 & $.019^{*}$ \\
\hline
\end{tabular}

Constant $(\mathrm{a})=0.211, \mathrm{R}=.787, \mathrm{R}^{2}=.609, \mathrm{SE}_{\text {est }}=.410, \mathrm{~F}=194.641, \mathrm{p} \leq .05$

** Statistical significance at 0.01

* Statistical significance at 0.05

Table 3 found that five predictor variables were able to jointly describe or predict the success of surveillance, prevention, and control of COVID-19 systems and protect people's rights in new normal by the virtual community of Primary Health Service Network, Mahasarakham Province was 60.90\% statistically significant (p. 05), and can write the forecasting equations in the form of raw scores and standard scores as follows; 
Forecasting equations in raw scores form

$\mathrm{Y}=0.211+0.215$ (Public communication) +0.283 (Participation in government measures) +0.117 (Information technology) +0.167 (Expectation of benefits) +0.142 (Readiness to respond to health care situations)

Forecasting equations in standard scores form

$\mathrm{Z}=0.294$ (Public communication) +0.256 (Participation in government measures) +0.125 (Information technology +0.148 (Expectation of benefits) +0.151 (Readiness to respond to health care situations)

4. The development model for surveillance, prevention, and control of COVID-19 systems and protect people's rights in new normal by the virtual community of Primary Health Service Network has a fair average of 3.50 5.00. They are considered to be more appropriate, possible at a higher level, and can be used to prototype surveillance, prevention, and control of COVID-19 policy proposals. And it can be expanded into practice in other provinces and health areas as well. It can also be a model to formulate policy proposals, prepare, develop capacity and strengthen national primary health care networks.

\section{Discussion}

The results of the research revealed the following points to discuss.

1. The success elements of surveillance, prevention, and control of COVID-19 and the protection of citizens' rights in new normal through the future search conference (FSC) are closely related to the virtual community and within the context of the healthcare network. It is also an important conditional factor that relates and correlates to the success indicator of the surveillance, prevention, control and protection of COVID-19 systems and the protection of citizens' rights of primary health networks. These lead to effective surveillance, prevention, and control of COVID-19 capabilities, consistent with the research of the Teerapong Tossawut and Piyakamon Mahiwan (2020) found that because The Coronavirus infectious Disease (COVID - 19) was taken place in Thailand since the end of the year 2019, had an effect on social quality of life, furthermore, it very high impacted many people, and caused problems such as public health problems, economic problems, and mental illness. Especially, social problems concerning socially vulnerable populations were found. Then, the important points about the development of social quality of life of people and the prevention of the spreading of coronavirus infectious disease (COVID - 19) include the development 1) on the social quality of life of people, 2) on the development of public health, 3) on the economy and society for general people, 4) on the adherence to the main controlling measures and supplementary measures in the area, 5) on the aggressive measures in monitoring and preventing the significant risk group, 6) on the following up of the relief of measures for businesses to be conducted and for activities to be performed in order to prevent the spreading of COVID - 19, 7) on measures preventing the impact of COVID - 19 in Thai society, 8) on the development of quality of life at work during the spreading of COVID-19 disease, and 9) on new normal behaviors and a new way of life after COVID - 19, which community participation of pandemic prevention. In the same way that the village health volunteers perform main roles in health promotion, surveillance, disease prevention and control, health rehabilitation, and consumer protection. Village health volunteers had successfully performed their roles in primary health care, family planning which can increase the rate of contraception and reduce the rate of birth, unwanted pregnancy, the reduction of human immunodeficiency virus infection, illness, mortality, and other matters. The association network and related stakeholders should improve specific performances among village health volunteers by applying the model of performance development for village health volunteers, focusing on bringing innovation and digital technology to healthcare services for the people in order to increase the efficiency and effectiveness of health promotion, surveillance, disease prevention and control, health rehabilitation, and consumer protection (Yutthana Yaebkai and Pramote Wongsawat. 2020). And consistent with the research of Jongkolnee Tuicharoen et al (2020) found that the concept of primary health care in primary care must be used in line with current health contexts. It describes the relationships between various parts of the community health system in a collaborative manner to promote better efficiency and effectiveness of the system. Due to the situation created by the new coronavirus 2019 species, or COVID-19, outbreak and pandemic, knowledge about prevention and taking care of people in the community are considered important aspects of how to slow the spread of the disease and to prevent the worsening of the epidemic, and ultimately stopping the spread of the virus. In the primary health system, those who play important roles in the community, such as village health volunteers, leadership, and people in every area, will be an important force to help prevent the disease's spread. The participation of people in the community is consistent with the context of the community concept and it can enable us to work faster, resulting in the creation of better health care systems, providing better social services, and improving the economy.

2. The development of information technology of the virtual community by developing the application \& digital platform is implemented through the Smart Phone all Android and Ios system through the application Line, Facebook, via the Internet as a communication medium in the application. The working system is consistent with 
the situation of the new coronavirus outbreak. This is one of the conditional factors affecting the COVID-19 surveillance system implemented through the digital application \& platform on the mobile phone of people traveling to and living in Mahasarakham Province. These were consistent with the research of Kanchana Panyathorn et al (2020) found that New normal of the participants were paying more attention to self-care by taking good care of personal hygiene, washing hand, wearing a mask as their daily costumes, eating cooked food, regular exercise, getting enough sleep to have more immunity, lessening social interaction, increasing home activity, taking care of the housing environment to allow good ventilation and using technology to communicate in daily life. For working behaviors, they practice restricting prevention behaviors by hand washing, maskwearing, social distancing, and preventing bringing disease to home.

3. The conditional factors that influence the success of the surveillance system are were; public communication, participation, and government measures, the information technology, the expectation of benefits, and the readiness to respond to health care situations by statistically significant $(\mathrm{p} . \leq 05)$. These variables were developed as a model for the development of surveillance, prevention, and control of COVID-19 systems and the protection of citizens' rights in new normal by a virtual community of an effective primary health service network, which was consistent with the research of Rawipron Rodchanaarcha et al (2021) found that setting up any isolation place for COVID-19 outside the hospital, there are 3 preparation aspects: appropriate area, competent staff, and enough equipment. The suitable care processes include: 1) the PUI criteria for hotel isolation,2) to designate a responsible person for the coordination process, 3) enough staff (doctor, nurse, and hotel staff), 4) a proper medical record system, 5) a care process, 6) medical supply management between hospital and hotel, 7) emergency management, and 8) safety management for preventing the spread of infection. In summary, the hotel structure is suitable for separating people who were exposed to the disease. However, for being successful in hotel isolation, everybody has to cooperate.

\section{Suggestions}

1. Policy recommendations: (1) for central government: the research results can be used to formulate surveillance policies and strategies, prevention, and control of COVID-19, and to protect the rights of the people, or to be used to define measures or operational guidelines of the Ministry of Health. It may also be used for other public interests that affect the quality of life or public health. (2) for the local government: The research findings are used to make administrative decisions in order to meet the realities of the rapidly changing and evolving COVID-19 epidemic situation. In addition, administrators can use research results into goals, directions, strategies, and content for more relevant management.

2. Practical recommendations: (1) The adoption of a new model for the development of surveillance, prevention, and control of COVID-19 and the protection of civil rights in a new way should be established, and the scope for the system operator and related personnel, system users must have knowledge and understanding, and most importantly, have a Smart Phone which It is a system for surveillance, prevention, control of COVID-19 and protection of the rights of the people, and most importantly, the system users can make their own voluntary and personal decisions. (2) Should bring this system to connect with Big Data, health, together with the development of the Application and Digital Platform of the surveillance system, prevent and control COVID-19 and protect people's rights in new normal. (3) The operating system implementation of surveillance, prevention, and control of the COVID-19 development model should be integrated with the operations of the family doctor team in the primary care unit. There is one people must have three personal doctors who are in line with the facilitation policy, and easy access to the service recipient can be applied locally if there is a preliminary agreement between system operators to integrate the Application and Platform Digital to be more cost-effective and efficient. 


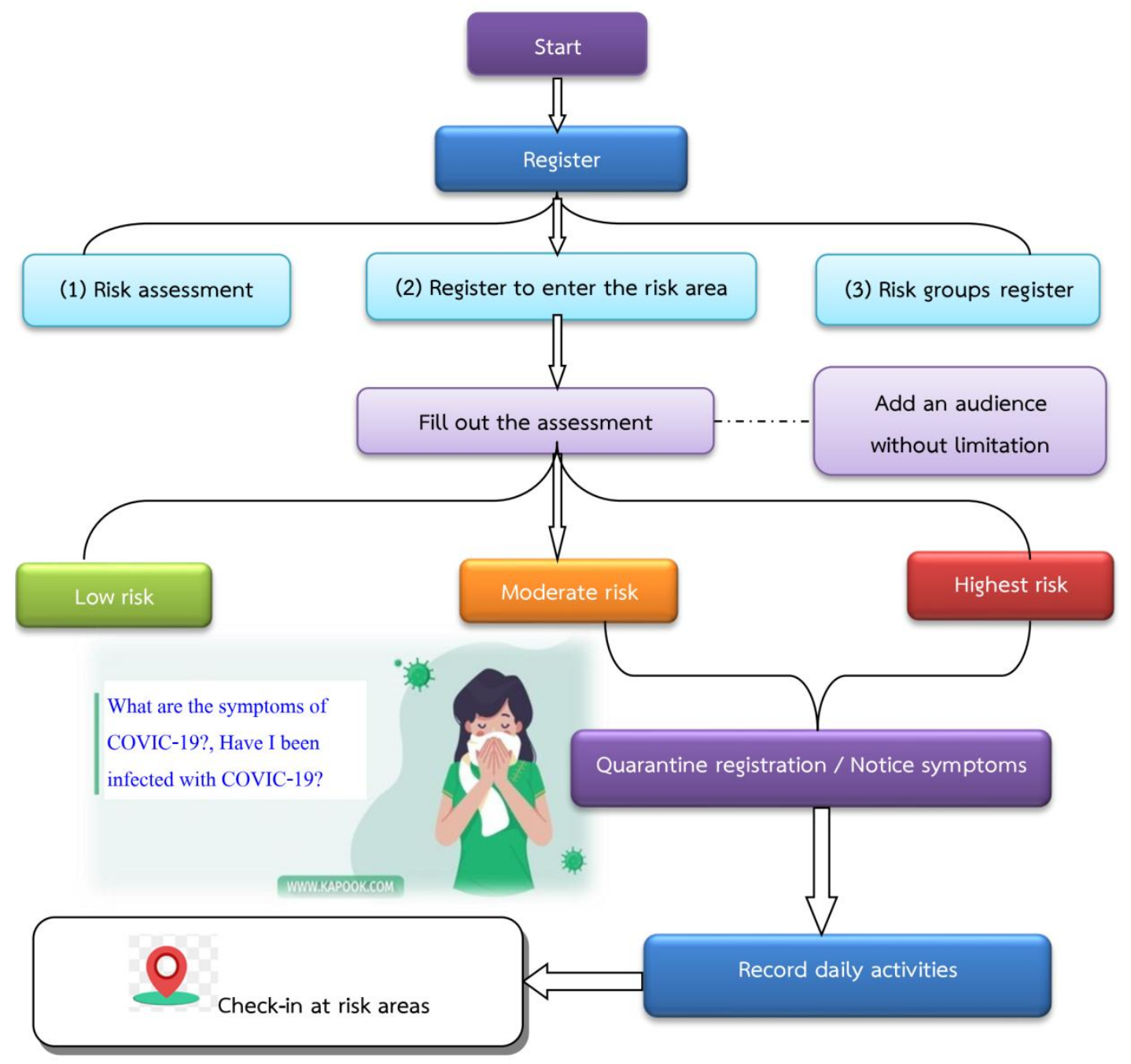

Diagram 1: APPLICATION: MSK_COVID_FIGHT

3. Suggestions for further research: (1) The efficacy and effectiveness of surveillance, prevention, and control of COVID-19 systems and the protection of civil rights in a new norm should be studied by the virtual community of primary health care networks or by expanding the scope of research in other dimensions. (2) There should be studied and developed using of Virtual Community to help develop health services of primary care networks in other areas or extend in-service units at all levels such as district health promotion hospitals, community hospitals, general hospitals, center hospitals in the event of an outbreak of New wave of COVID-19 disease. (3) Should study the process of driving health policy integrated with the Future Search Conference (FSC) by applying Virtual Community at the provincial/regional health and national level, which is connected to the health Big Data system of primary health care networks or primary care units with health service units at all levels as an integrated management tool and monitoring and directing the health operations of the health service units.

\section{Acknowledgment}

Thank you very much to the Permanent Secretary of the Ministry of Public Health, Mahasarakham Province Public Health Doctor, which is the target area for the research project and provided support for implementing this research project. All hospitals/health service units, District Public Health Office, Tambon Health Promoting Hospital, Primary Health Service Network, related workgroups in the Provincial Public Health Office, and local government organizations. (Provincial Administrative Organization, Municipality, and Subdistrict Administrative Organization), Government organizations in the province, the public sector, and medical and public health personnel at the provincial / district / sub-district levels, the village health volunteers, Family doctors of the Primary Health Service Network, Public Health Academic Office personnel, Office of the Permanent Secretary of Public Health, including all stakeholders supporting the successful completion of the research project..

\section{References}

Denizen N.K. (1970). The Research Act: A Theoretical Introduction to Sociological Methods. Chicago: Aldine. 
Department of Disease Control, Ministry of Public Health. (2020). The 2019 Coronavirus Disease Prevention and Control Manual for People.Bangkok: Printing House, Agricultural Cooperative Association of Thailand, Ltd.

Jongkolnee Tuicharoen, Nichakhan Wongprakhob, Krittakorn Munsraket and Tidarat Nimkratoke. (2020). "Management of the COVID -19 in Primary Health Care Settings".Journal of Health Science Boromarajonani College of Nursing Sunpasitthiprasong, 3(4):1-20.

Kanchana Panyathorn, Sirinrat Ninphupataweechot, Chonlakarn Songsri, Kamonthip Tanglakmankhong and Sauwalak Tajang. (2020). "New normal among Health Personnel to Prevent Coronavirus Disease 2019: A Study of Fort Prachaksilapakom Hospital, Udon Thani Province". Journal of Nursing and Health Care, 38 (4): 45-53.

Krejcie, R.V., \& D.W. Morgan. (1970). "Determining Sample Size for Research Activities”. Educational and Psychological Measurement. 30 (3): 607 - 610.

Ministry of Public Health. (2020). "Notification of the Ministry of Public Health Re: Names and Important Symptoms of Dangerous Communicable Diseases (No.3)" February 26, 2020. [Online] http://ddc.moph.go.th/uploads /files/10020200330051455.pdf [ September 29, 2020]

Rawipron Rodchanaarcha, Noppcha Singweratham, Chawika Wannaro and Metha Kiatmolee. (2021). "COVID19 Outbreak: Guideline on Local Quarantine for both Inbound and Outbound Migrants from Epidemic Areas Using Hotel Isolation in Sadao District of Songkhla Province". The Southern College Network Journal of Nursing and Public Health, 8(1): 337-348

Sanya Kenaphoom, Suthinee Atthakorn, Sovalakk Kosolkittiamporn, Chakorn Kaiyanan, Kanlayani Charoensopharat and Thanatporn Khattiyanon. (2020). "Decoding of Tactical Strategy Establish from the Research Based”, Palarch's Journal of Archaeology of Egypt/Egyptology, 17 (7): 9614-9636.

Teerapong Tossawut and Piyakamon Mahiwan. (2020). "THE DEVELOPMENT OF SOCIAL QUALITY OF LIFE OF PEOPLE AND THE PREVENTION OF THE SPREADING OF CORONAVIRUS INFECTIOUS DISEASE (COVID - 19)", Journal of MCU Nakhondhat, 7 (9): 40-55.

World Health Organization. (2020). "WHO Timeline - COVID-191.”. [Online] https://www.who.int/news/item/27-04-2020-who-timeline---covid-19.[September 29,2020]

Yutthana Yaebkai and Pramote Wongsawat. (2020). "Main Role Performances of Village Health Volunteers". JOURNAL OF PHRAPOKKLAO NURSING COLLEGE, 31 (2): 269-279. 